\title{
A paediatrician is hundred years young
}

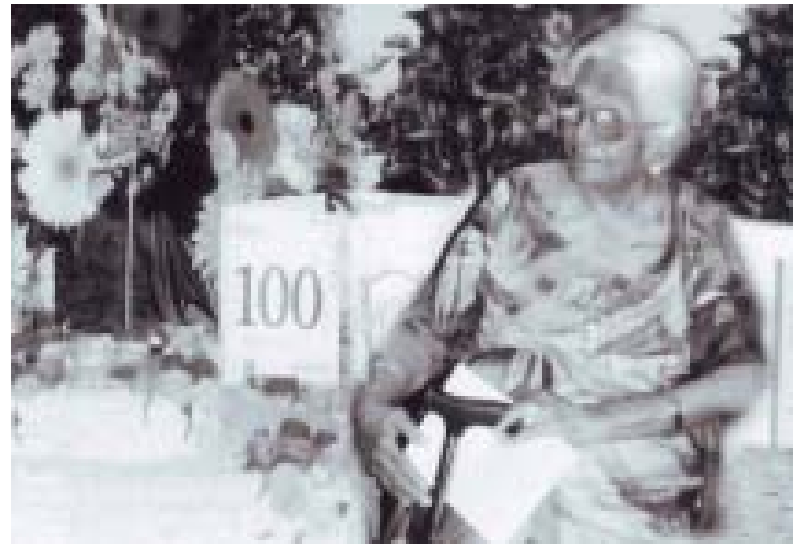

Dr. Grace Barr Kumarakulasinghe LMS (Cey) FRCP (Edin) DCH (Lond) who celebrated her 100th birthday on August 7th 2008, is perhaps the oldest member of the medical profession, in Sri Lanka. Cognitively intact and physically independent "Dr Barr Kum" marked the occasion with a simple thanksgiving ceremony in her home, which devoted family and loving friends had decked with flowers and festooned with party décor. Among the many congratulatory messages received were those from the Queen of England and the President of the Royal College of Physicians of Edinburgh. On this special occasion, it is fitting that we look back at the life and work of this remarkable paediatrician who is a past president of the Sri Lanka Paediatric Association, and founder Joint Editor of the Ceylon Journal of Obstetrics and Gynaecology.

The world Dr. Barr Kumarakulasinghe was born into, in the early 20 th century, as the seventh child of G.V. and Alice Sinnathamby, would be largely unrecognizable by the children of today. She recalls a happy childhood in the quiet surroundings in residential Colombo North and chuckles at the transformation in the capital city saying "I remember Colombo 7 as a jungle".

She sat her matriculation examination from Ladies College, obtaining a first class but was coaxed into a career in medicine, abandoning plans of reading for a Degree in English Literature, by her brother Dr. G. S. Sinnathamby (later, Senior Surgeon, General Hospital, Colombo). A decision she has not regretted for a moment.

At the time, science was not taught in girl's schools and it was in university that she first learnt this discipline. She qualified as a doctor with First Class Honours from the Colombo Medical School and recounts obtaining her first job thus: "Even before my results were out, the doctor in-charge of the OPD in General Hospital put my name down to act for him, because he wanted long leave over the Sinhalese New Year". Her protests of "not having passed out yet" were calmly met with "I know you will". "In those days there was no compulsory internship for doctors" explains Dr. Barr Kumarakulasinghe.

Her service at the Lady Ridgeway Hospital (LRH) began when it was "a small place consisting of a single two storey building in premises, shared with Lady Havelock Hospital that took in gynaecology cases. Lady Ridgeway admitted children and it was her duty to cover both hospitals. "We worked 72 hour shifts followed by half a day off for a monthly salary of Rs 100 " recalls this remarkable lady. Women doctors were scarce, and as Woman Medical Officer (WMO), Dr. Barr Kumarakulasinghe served in many outposts in this country prior to travel abroad for postgraduate studies.

She was one of two lady paediatricians who first returned to Ceylon, in the same year. Although armed with the MRCP (Edin) and DCH (Lond) she found it no easy task to be placed in charge of a ward at the LRH, in a male dominated profession. Comments of "you are only a woman" was followed by a posting to Castle Street Maternity Hospital instead. Thus she became the first paediatrician in this country to record morbidity and mortality of the newborn. Her Presidential Address to the Ceylon Association of Paediatricians was on the morbidity patterns of the newborn. This pioneering contribution was acclaimed by the then Director of Health Services Dr. V. T. Herat Gooneratne, who unveiled her portrait at the Lady Ridgeway Childrens Hospital on her retirement.

When I first met Dr. Grace Barr Kumarakulasinghe in her 98th year, she proved to be a living link to the history of paediatrics of this country which I was researching. Those of us who had the good fortune of hearing the impromptu birthday speech delivered, were left in awe at her cheerful disposition, unfaltering optimism and complete lack of animosity. Her unwavering faith in God's love brings to mind the promise embodied in those words of Robert Browning :

\section{Grow old along with me}

The best is yet to be!

May Dr. Barr Kumarakulasinghe enjoy continued good health and happiness!

Manouri P Senanayake, Department of Paediatrics, Faculty of Medicine, University of Colombo, Sri Lanka. E-mail<paed_colombo@yahoo.com>. 